\title{
Multidrug-Resistant Organism Infections in US Nursing Homes: A National Study of Prevalence, Onset, and Transmission across Care Settings, October 1, 2010-December 31, 2011
}

\author{
Daver Kahvecioglu, PhD; ${ }^{1}$ Kalpana Ramiah, DrPH, MPH, MSc, CPH, CHES; ${ }^{2}$ Darcy McMaughan, PhD; ${ }^{3}$ \\ Steven Garfinkel, PhD; ${ }^{2}$ Veronica E. McSorley, MPH; ${ }^{2}$ Quy Nhi Nguyen, MPH; ${ }^{2}$ Manshu Yang, PhD; ${ }^{2}$ \\ Christopher Pugliese, MPP; ${ }^{2}$ David Mehr, MD, MS; ${ }^{4}$ Charles D. Phillips, PhD, MPH ${ }^{3}$
}

\begin{abstract}
OBjective. To understand the prevalence of multidrug-resistant organism (MDRO) infections among nursing home (NH) residents and the potential for their spread between NHs and acute care hospitals (ACHs).

METHODs. Descriptive analyses of MDRO infections among NH residents using all NH residents in the Long-Term Care Minimum Data Set (MDS) 3.0 between October 1, 2010 and December 31, 2011.

RESULTS. Analysis of MDS data revealed a very high volume of bidirectional patient flow between NHs and ACHs, indicating the need to study MDRO infections in NHs as well as in hospitals. A total of $4.24 \%$ of NH residents had an active MDRO diagnosis on at least 1 MDS assessment during the study period. This rate significantly varied by sex, age, urban/rural status, and state. Approximately $2 \%$ of $\mathrm{NH}$ discharges to $\mathrm{ACHs}$ involved a resident with an active diagnosis of infection due to MDROs. Conversely, $1.8 \%$ of $\mathrm{NH}$ admissions from an $\mathrm{ACH}$ involved a patient with an active diagnosis of infection due to MDROs. Among residents who acquired an MDRO infection during the study period, $57 \%$ became positive in the $\mathrm{NH}, 41 \%$ in the $\mathrm{ACH}$, and $2 \%$ in other settings (eg, at a private home or apartment).

CONCLUSION. Even though NHs are the most likely setting where residents would acquire MDROs after admission to an NH (accounting for $57 \%$ of cases), a significant fraction of NH residents acquire MDRO infection at ACHs (41\%). Thus, effective MDRO infection control for $\mathrm{NH}$ residents requires simultaneous, cooperative interventions among $\mathrm{NHs}$ and $\mathrm{ACH}$ s in the same community.
\end{abstract}

Infect Control Hosp Epidemiol 2014;35(S3):S48-S55

Healthcare-associated infections (HAIs) are infections that patients acquire during the course of receiving healthcare treatment for other conditions. The Centers for Disease Control and Prevention estimated that the 1.74 million HAIs reported in 2007 cost US hospitals between $\$ 28.4$ and $\$ 33.8$ billion. ' In response, the US government instituted policy changes to reduce the incidence of HAIs. Under the Affordable Care Act, states were required to start reporting their rates of HAIs in 2012. ${ }^{2}$ Beginning in 2015, hospitals in the quartile with the highest number of HAIs will have their Medicare payments reduced by $1 \% .^{3}$

Two-thirds of all HAIs come from just 6 multidrug-resistant organisms (MDROs). ${ }^{4}$ These include Enterococcus species (vancomycin-resistant enterococci [VRE]), Staphylococcus aureus (methicillin-resistant $S$. aureus [MRSA], vancomycinintermediate $S$. aureus [VISA], or vancomycin-resistant $S$. aureus [VRSA]), Klebsiella pneumoniae, Acinetobacter baumannii, Pseudomonas aeruginosa, and Enterobacter species (extended-spectrum $\beta$-lactamase-producing gram-negative bacilli [ESBL] and fluoroquinolone-resistant $P$. aeruginosa).

The prevalence of MDROs in medical centers has increased steadily. ${ }^{5}$ Older patients are among the main reservoirs of MDROs in the hospital. In a study conducted in a 620 -bed tertiary care healthcare facility in Boston, admission prevalence per 1,000 for MRSA, VRE, and multidrug-resistant gram-negative bacteria (MDRGN) was consistently higher among the elderly population than among other age groups. Furthermore, admission prevalence among the elderly population increased significantly over time for VRE (from 0.89 cases per 1,000 admissions in 1998 to 3.62 cases per 1,000 admissions in 2009) and MDRGN (1.41 cases per 1,000 admissions in 1998 to 11.33 cases per 1,000 admissions in 2009). The admission prevalence of MRSA increased until 2003 and then decreased (6.6 cases per 1,000 admissions in 1998, 24.8 in 2003, and 16.3 in 2009). ${ }^{6}$

It is not surprising that MDROs are also a serious concern

Affiliations: 1. Fannie Mae, Washington, DC; 2. American Institutes for Research, Washington, DC; 3. Texas A\&M University, School of Public Health, College Station, Texas; 4. University of Missouri, School of Medicine, Columbia, Missouri.

Received April 4, 2014; accepted June 8, 2014; electronically published September 15, 2014.

(C) 2014 by The University of Chicago. All rights reserved. 0899-823X/2014/35S3-0008\$15.00. DOI: 10.1086/677835 
TABLE 1. Distribution of Nursing Home Residents by Demographic Characteristic and Prevalence of Multidrug-Resistant Organisms (MDROs) among Residents in Each Category

\begin{tabular}{|c|c|c|}
\hline Demographic characteristic & $\begin{array}{l}\text { Overall nursing } \\
\text { home resident population }\end{array}$ & $\begin{array}{l}\text { Residents who } \\
\text { ever received } \\
\text { a diagnosis } \\
\text { involving MDRO }\end{array}$ \\
\hline Total & $100(4,165,596)$ & $4.24(176,806)$ \\
\hline \multicolumn{3}{|l|}{ Age, years } \\
\hline Mean $\pm \mathrm{SD}$ & $77.43 \pm 13.36$ & $74.81 \pm 14.22$ \\
\hline$\leq 17$ & $0.17(7,153)$ & $3.54(253)$ \\
\hline $18-29$ & $0.35(14,617)$ & $7.12(1,041)$ \\
\hline $30-39$ & $0.69(28,549)$ & $7.52(2,148)$ \\
\hline $40-49$ & $2.28(95,167)$ & $6.76(6,431)$ \\
\hline $50-54$ & $2.78(115,682)$ & $5.90(6,821)$ \\
\hline $55-60$ & $4.13(171,955)$ & $5.46(9,388)$ \\
\hline $60-64$ & $5.73(238,778)$ & $5.16(12,328)$ \\
\hline $65-69$ & $7.95(331,122)$ & $4.94(16,354)$ \\
\hline $70-74$ & $9.92(413,202)$ & $4.56(18,839)$ \\
\hline $75-79$ & $13.36(556,487)$ & $4.25(23,654)$ \\
\hline $80-84$ & $17.88(744,769)$ & $3.99(29,681)$ \\
\hline $85-89$ & $18.63(775,809)$ & $3.71(28,759)$ \\
\hline $90-94$ & $11.56(481,576)$ & $3.28(15,801)$ \\
\hline $95-99$ & $3.90(162,413)$ & $2.89(4,701)$ \\
\hline$\geq 100$ & $0.67(27,950)$ & $2.11(591)$ \\
\hline \multicolumn{3}{|l|}{ Sex } \\
\hline Male & $35.93(1,496,203)$ & $5.24(78,413)$ \\
\hline Female & $64.07(2,668,462)$ & $3.69(98,355)$ \\
\hline \multicolumn{3}{|l|}{ Race/ethnicity } \\
\hline White & $80.04(3,328,527)$ & $4.25(141,353)$ \\
\hline Black & $10.92(454,213)$ & $4.22(19,148)$ \\
\hline Hispanic & $4.34(180,630)$ & $4.16(7,509)$ \\
\hline Asian & $1.50(62,364)$ & $3.70(2,309)$ \\
\hline American Indian or Alaska Native & $0.39(16,322)$ & $5.18(845)$ \\
\hline Native Hawaiian/ Pacific Islander & $0.30(12,291)$ & $4.21(517)$ \\
\hline \multicolumn{3}{|l|}{ Marital status } \\
\hline Never married & $14.25(576,833)$ & $4.87(28,074)$ \\
\hline Married & $30.54(1,236,230)$ & $4.47(55,302)$ \\
\hline Widowed & $43.04(1,741,940)$ & $3.69(64,364)$ \\
\hline Separated & $1.33(53,955)$ & $4.87(2,626)$ \\
\hline Divorced & $10.84(438,704)$ & $4.82(21,148)$ \\
\hline \multicolumn{3}{|l|}{ Urban/rural } \\
\hline Urban & $81.15(3,380,273)$ & $4.38(148,133)$ \\
\hline Rural & $18.85(785,323)$ & $3.65(28,673)$ \\
\hline Overall & $100(4,165,596)$ & $4.24(176,806)$ \\
\hline
\end{tabular}

NOTE. Data are percentage (no.) of residents, unless otherwise indicated. SD, standard deviation.

in long-term care settings, especially those that serve the frail elderly population. ${ }^{7}$ In a screening performed in a 120-bed skilled nursing facility in the absence of a clinical "outbreak," $43 \%$ of residents were found to be carrying a drug-resistant organism. Once introduced in a long-term care facility (LTCF), MDROs tend to become endemic. ${ }^{8}$ Having stayed in a LTCF is a risk factor for invasive MRSA infection. In a study of patient intake forms at a 980-bed tertiary care hospital between 1996 and 1997, patients admitted from nursing homes (NHs) were 6.4 times more likely to have MRSA than those who had come to the hospital from other places. ${ }^{9} \mathrm{NH}$ often have a higher prevalence of MRSA colonization than hospitals and ICUs. ${ }^{10,11}$ More than half the residents of LTCFs are thought to harbor MDRGN..$^{12-14}$

It is important to distinguish between colonization and clinical infection. Colonization is an asymptomatic presence 
TABLE 2. Distribution of Nursing Home Residents by State and Prevalence of Multidrug-Resistant Organisms (MDROs) among Residents in Each State

\begin{tabular}{|c|c|c|}
\hline \multirow[b]{2}{*}{ State } & \multicolumn{2}{|c|}{ Percentage (no.) of residents } \\
\hline & Overall nursing home population & $\begin{array}{l}\text { Residents who ever received } \\
\text { a diagnosis involving MDRO }\end{array}$ \\
\hline $\mathrm{AK}$ & $0.03(1,436)$ & $5.92(85)$ \\
\hline $\mathrm{AL}$ & $1.53(63,752)$ & $1.87(1,192)$ \\
\hline AR & $0.96(40,194)$ & $3.13(1,259)$ \\
\hline $\mathrm{AZ}$ & $1.49(62,224)$ & $4.49(2,794)$ \\
\hline $\mathrm{CA}$ & $8.66(360,918)$ & $4.05(14,610)$ \\
\hline $\mathrm{CO}$ & $1.28(53,262)$ & $2.41(1,285)$ \\
\hline $\mathrm{CT}$ & $1.89(78,671)$ & $5.67(4,461)$ \\
\hline DC & $0.16(6,732)$ & $3.46(233)$ \\
\hline $\mathrm{DE}$ & $0.31(13,009)$ & $4.40(572)$ \\
\hline FL & $6.65(276,989)$ & $4.05(11,231)$ \\
\hline GA & $2.04(84.792)$ & $2.86(2,426)$ \\
\hline HI & $0.28(11,511)$ & $2.88(331)$ \\
\hline IA & $1.35(56,202)$ & $3.64(2,048)$ \\
\hline ID & $0.38(15,852)$ & $3.69(585)$ \\
\hline IL & $4.97(207,050)$ & $5.42(11,231)$ \\
\hline IN & $2.56(106,604)$ & $3.20(3,414)$ \\
\hline KS & $1.05(43,914)$ & $3.38(1,484)$ \\
\hline KY & $1.54(64,308)$ & $4.42(2,840)$ \\
\hline $\mathrm{LA}$ & $1.24(51,722)$ & $2.49(1,286)$ \\
\hline MA & $3.24(134,782)$ & $6.15(8,289)$ \\
\hline $\mathrm{MD}$ & $2.01(83,589)$ & $5.43(4,540)$ \\
\hline $\mathrm{ME}$ & $0.54(22,527)$ & $3.25(733)$ \\
\hline MI & $3.25(135,188)$ & $3.69(4,984)$ \\
\hline $\mathrm{MN}$ & $2.09(86,946)$ & $3.86(3,354)$ \\
\hline MO & $2.31(96,317)$ & $3.31(3,190)$ \\
\hline MS & $0.84(34,932)$ & $2.42(847)$ \\
\hline MT & $0.31(12,814)$ & $2.95(378)$ \\
\hline $\mathrm{NC}$ & $2.74(114,340)$ & $3.34(3,822)$ \\
\hline ND & $0.30(12,396)$ & $5.17(641)$ \\
\hline $\mathrm{NE}$ & $0.79(32,957)$ & $3.91(1,290)$ \\
\hline $\mathrm{NH}$ & $0.47(19,376)$ & $5.85(1,134)$ \\
\hline NJ & $3.72(155,099)$ & $4.86(7,534)$ \\
\hline NM & $0.44(18,274)$ & $2.99(546)$ \\
\hline NV & $0.51(21.103)$ & $6.33(1,335)$ \\
\hline NY & $6.93(288,786)$ & $4.41(12,749)$ \\
\hline $\mathrm{OH}$ & $5.75(239,316)$ & $4.74(11,351)$ \\
\hline $\mathrm{OK}$ & $1.11(46,137)$ & $2.19(1,009)$ \\
\hline OR & $0.87(36,145)$ & $2.77(1,003)$ \\
\hline PA & $5.75(239,505)$ & $5.68(13,612)$ \\
\hline RI & $0.55(22,713)$ & $11.42(2,593)$ \\
\hline $\mathrm{SC}$ & $1.22(50,877)$ & $2.54(1,292)$ \\
\hline $\mathrm{SD}$ & $0.32(13,323)$ & $3.73(497)$ \\
\hline $\mathrm{TN}$ & $2.13(88,575)$ & $3.55(3,147)$ \\
\hline $\mathrm{TX}$ & $5.79(241,067)$ & $3.21(7,736)$ \\
\hline UT & $0.60(24,825)$ & $2.40(595)$ \\
\hline VA & $2.26(93,947)$ & $6.34(5,958)$ \\
\hline VT & $0.21(8,823)$ & $6.28(554)$ \\
\hline WA & $1.7(70,848)$ & $4.52(3,204)$ \\
\hline WI & $2.13(88,687)$ & $3.75(3,324)$ \\
\hline WV & $0.63(26,431)$ & $7.80(2,062)$ \\
\hline WY & $0.14(5,809)$ & $2.34(136)$ \\
\hline Overall & $100(4,165,596)$ & $4.24(176,806)$ \\
\hline
\end{tabular}


TABLE 3. Distribution of Nursing Home Residents by US Census Bureau Region and Division and Prevalence of Multidrug-Resistant Organisms (MDROs) among Residents in Each Region and Division

\begin{tabular}{|c|c|c|}
\hline \multirow[b]{2}{*}{ Geographic area } & \multicolumn{2}{|c|}{ Percentage (no.) of residents } \\
\hline & $\begin{array}{l}\text { Overall nursing } \\
\text { home population }\end{array}$ & $\begin{array}{c}\text { Residents who } \\
\text { ever received } \\
\text { a diagnosis } \\
\text { involving MDRO }\end{array}$ \\
\hline \multicolumn{3}{|l|}{ Census region } \\
\hline Midwest & $26.86(1,118,900)$ & $4.18(46,808)$ \\
\hline Northeast & $23.29(970,282)$ & $5.32(51,659)$ \\
\hline South & $33.16(1,381,393)$ & $3.72(51,452)$ \\
\hline West & $16.68(695,021)$ & $3.87(26,887)$ \\
\hline \multicolumn{3}{|l|}{ Census division } \\
\hline \multicolumn{3}{|l|}{ Midwest } \\
\hline West North Central & $8.21(342,055)$ & $3.66(12,504)$ \\
\hline East North Central & $18.65(776,845)$ & $4.42(34,304)$ \\
\hline \multicolumn{3}{|l|}{ Northeast } \\
\hline Middle Atlantic & $16.41(683,390)$ & $4.96(33,895)$ \\
\hline New England & $6.89(286,892)$ & $6.19(17,764)$ \\
\hline \multicolumn{3}{|l|}{ South } \\
\hline West South Central & $9.10(379,120)$ & $2.98(11,290)$ \\
\hline East South Central & $6.04(251,567)$ & $3.19(8,026)$ \\
\hline South Atlantic & $18.02(750,706)$ & $4.28(32,136)$ \\
\hline \multicolumn{3}{|l|}{ West } \\
\hline Mountain & $5.14(214,163)$ & $3.57(7.654)$ \\
\hline Pacific & $11.54(480,858)$ & $4.00(19,233)$ \\
\hline Overall & $100(4,165,596)$ & $4.24(176,806)$ \\
\hline
\end{tabular}

of pathogenic bacteria in culture specimens. Clinical guidelines for managing infections in LTCFs suggest that, in most cases, colonization with no clinical symptoms of infection should not be treated, to minimize the risk of creating MDROs. Clinical infections (ie, those that exhibit symptoms) should be treated in most cases. ${ }^{15,16}$ Furthermore, MDROcolonized LTCF residents can eventually exhibit symptoms that require treatment according to guidelines ${ }^{17}$ and can become the source of transmission to other healthcare settings. ${ }^{18-28}$

The increasing prevalence of clinical MDRO infections is associated with increased lengths of stay, costs, and mortality. ${ }^{29}$ The demand for places in LTCFs will grow substantially in the next 2 decades as the large population cohort born before 1964 ages. It is estimated that people using paid LTCFs will double to 27 million by $20500^{30}$ Thus, the cost and quality of care, the risk of HAIs, and the prevalence of MDROs in LTCFs are important issues for society.

There are several gaps in the literature. First, the literature does not examine the patterns of transmission to and from LTCFs and ACHs. Second, few earlier studies reported on the racial or geographic disparities in MDRO prevalence. Third, we were not able to find any study that described the transmission of the infection and its pattern of transmission across settings.

\section{METHODS}

This study uses the Centers for Medicare and Medicad Services (CMS) Long Term Care Minimum Data Set (MDS). ${ }^{31}$ MDS is a standardized, primary screening and assessment tool that measures physical, clinical, psychological, and psychosocial functional status and life care wishes of all residents (regardless of payer) of Medicare- or Medicaid-certified NHs. MDS data include a resident-level active MDRO infection indicator measured at admission and periodically thereafter (at least quarterly), the type of setting from which the resident is admitted, and the type of setting to which the resident is discharged. These settings include community (private home or apartment, board or care, assisted living, and group home), another $\mathrm{NH}$ or swing bed facility, $\mathrm{ACH}$, psychiatric hospital, inpatient rehabilitation facility, intellectual disability or developmental disability facility, hospice, and long-term care hospital. Although it would be desirable to study the rates of both asymptomatic and symptomatic infections, the MDS captures only clinically symptomatic infections. Although it would be useful to include all types of LTCFs in the study, MDS data are collected only in Medicare- and Medicaidcertified NHs.

For this study, we used national MDS data for 15 months from October 1, 2010, through December 31, 2011. During this period, there were 135 days, on average, between MDS assessments, with a median of 51 days. There were approximately 16,000 facilities with at least 1 MDS record. There was at least 1 assessment record for 4,165,596 residents. On average, residents had 4.6 assessments with a median of 4 during this time period.

Our analysis sought to address the following 6 research questions: (1) What is the frequency of $\mathrm{NH}$ admissions from ACHs and discharges to ACHs? (2) What percentage of hospital episodes involving adults (more than 65 years old) in the United States in 2011 were either immediately preceded by an NH discharge to the hospital or immediately succeeded by admission to an NH? (3) What is the national overall prevalence of MDRO infections among NH residents, and are there demographic or geographic disparities? (4) How many $\mathrm{NH}$ admissions and discharges from hospitals are of individuals who have MDRO infections? (5) How many $\mathrm{NH}$ residents acquire MDRO infections after $\mathrm{NH}$ admission? (6) How long does it take for $\mathrm{NH}$ residents to acquire MDRO infections in NHs?

We used quantitative descriptive analysis to calculate prevalence across a number of strata. We also developed 2 algorithms to identify the possible source setting of the infection and define a unit of observation for analyzing the onset of the infection. The counts and rates reported are for the US population of $\mathrm{NH}$ residents during the period October 1, 2010, through December 31, 2011. Because control of MDROs is a major patient safety initiative for $\mathrm{NHs}$ and hospitals nationwide, we expect these rates to improve with time. Thus, we are reluctant to imply that they reflect a larger 
TA BLE 4. Multidrug-Resistant Organism (MDRO) Data by Quarter

\begin{tabular}{lcccc}
\hline $\begin{array}{c}\text { Saseline quarter } \\
\text { (average start date: } \\
\text { mid-November 2010) }\end{array}$ & $\begin{array}{c}\text { Follow-up quarter 1 } \\
\text { (average start date: } \\
\text { mid-February 2011) }\end{array}$ & $\begin{array}{c}\text { Follow-up quarter 2 } \\
\text { (average start date: } \\
\text { mid-May 2011) }\end{array}$ & $\begin{array}{c}\text { Follow-up quarter 3 } \\
\text { (average start date: } \\
\text { mid-August 2011) }\end{array}$ \\
\hline $\begin{array}{l}\text { MDRO infection prevalence } \\
\text { MDRO infection rate (new infections) } \\
\begin{array}{l}\text { among residents with no infection } \\
\text { reported at baseline }\end{array}\end{array}$ & 1.38 & 1.34 & 1.26 & 1.32 \\
$\begin{array}{l}\text { Cumulative MDRO infection rate } \\
\text { among residents with no infection } \\
\text { reported at baseline }\end{array}$ & $\ldots$ & 0.70 & 0.80 & 0.93 \\
\hline
\end{tabular}

population of persons who might reside in NHs at other time periods and have accordingly chosen to treat the residents of US NHs during this period as a finite census population. As is appropriate for a finite census, we have not computed variances or tested for the statistical significance of the differences observed between population groups. These rates have not been reported previously and serve as a baseline against which future counts and estimates from other sources can be compared.

\section{RESULTS}

\section{Transitions between NHs and ACHs}

During the 15-month study period, there were 2,102,128 discharges from NHs to ACHs for 1,279,608 unique $\mathrm{NH}$ residents. These discharges represent $45 \%$ of all discharges from NHs and $30.7 \%$ of all residents who were discharged at least once.

During this period, $90 \%$ of all admissions to $\mathrm{NHs}$ $(4,399,280$ admissions) came from ACHs. Approximately $2,914,705 \mathrm{NH}$ residents ( $62.1 \%$ of all residents) were admitted to an $\mathrm{NH}$ immediately after discharge from $\mathrm{ACH}$.

To understand what these results could mean for all hospitals, we extrapolated the study's findings to data from the Agency for Healthcare Research and Quality's (AHRQ's) Healthcare Cost and Utilization Project (HCUP). AHRQ's HCUP reports that there were a total of $13,816,586$ discharges of older adults from all hospitals in the United States in 2011. According to our calculations from MDS data for the same period, at least $2,965,678$ of such hospital episodes $(21.5 \%)$ were either immediately preceded by an $\mathrm{NH}$ discharge to the hospital or immediately succeeded by admission to an $\mathrm{NH}$. Such hospital episodes were experienced by 2,046,501 NH residents $(69 \%)$ who were 65 years of age and older.

These findings show that there is a very high volume of patient flow between NHs and hospitals. This indicates dramatic potential of MDRO transmission across these settings. Thus, MDRO infections in NHs are expected to have strong implications for MDRO infections in hospitals.

\section{Prevalence of MDROs}

As displayed in Table 1, $4.24 \%$ of $\mathrm{NH}$ residents had a MDRO on at least 1 assessment during their $\mathrm{NH}$ stay. Male residents had a higher rate of infection than female residents $(5.24 \%$ and $3.69 \%$, respectively). American Indian and Alaska Natives had the highest rate of infection at $5.18 \%$, and Asians had the lowest rate $(3.70 \%)$. Infection rate by marital status varied by just over $1 \%$, with the lowest rate among widowed residents $(3.69 \%)$ and the highest rate among never married and separated residents (both at $4.87 \%$ ). Residents in an urban setting had a rate of $4.28 \%$, and those in a rural setting had a rate of $3.65 \%$.

The rate of infection in NHs varied by age group, with the lowest prevalence among the oldest residents (those over 100 years old) at $2.11 \%$ and the highest among those $30-39$ years old $(7.52 \%)$ and $18-29$ years old $(7.12 \%)$. The age bands that represented the largest proportions of the population were $75-79$ years old $(13.36 \%), 80-84$ years old $(17.88 \%), 85-89$ years old $(18.63 \%)$, and $90-94$ years old $(11.56 \%)$, and prevalence in these groups was $4.25 \%, 3.99 \%, 3.71 \%$, and $3.28 \%$, respectively.

As Table 2 shows, there was a large variation in MDRO prevalence among the states, with nearly 11 percentage points separating the state with the lowest prevalence (Alabama, at $1.87 \%$ ) and the state with the highest prevalence state (Rhode Island, at $11.42 \%$ ).

In addition to large variations between states, there were also regional variations, as exhibited in Table 3. The Northeast was the only region with MDRO prevalence above the national rate $(5.32 \%$ vs $4.24 \%)$. Of the remaining 3 regions, the South had the lowest prevalence at $3.72 \%$, the West had a prevalence of $3.87 \%$, and the Midwest, at $4.18 \%$, had a prevalence around the national average.

Looking at more granular data reveals divisions that are driving the Regional results. The South's low prevalence was fairly uniform across its 3 divisions (ie, West South Central, East South Central, and South Atlantic). The West South Central Division within the South had the lowest prevalence at $2.98 \%$, with East South Central immediately behind at $3.19 \%$. The South Atlantic was at $4.28 \%$, close to the national 
rate. However, at the other end of the spectrum, the division with highest prevalence (New England, at 6.19\%) was the main reason that the Northeast Region had the highest prevalence among the regions. Within New England, all but 1 of the 6 States had very high prevalences.

\section{MDRO Acquisition Rates}

The acquisition of MDROs in NHs can be measured by identifying residents who were MDRO negative at their first assessment after admission to the NH and MDRO positive at a subsequent assessment, or those who were MDRO positive at their first assessment after admission but for whom the time between admission and first assessment is longer than 7 days. We estimated the frequency of MDRO acquisition in ACHs by identifying residents who were already MDRO positive on their first assessment after readmission to the $\mathrm{NH}$ from the hospital and for whom the time between the readmission date and the date of the first assessment is shorter than or equal to 7 days. If residents were already MDRO positive at their first assessment, which was usually administered several days after the readmission to the $\mathrm{NH}$, it is difficult to identify whether the MDRO onset occurred after returning to the $\mathrm{NH}$ or before returning. We therefore required a "clean period" of 7 days. If residents stayed in the $\mathrm{NH}$ more than 7 days and were MDRO positive at their first assessment in the $\mathrm{NH}$, then we attributed the acquisition of MDRO to the NH; on the contrary, if their stay in NH before the first assessment was shorter than 7 days and they were MDRO positive at the first assessment, we attributed the acquisition of MDRO to other settings outside the NH. The method of estimating acquisition rates in the NHs is reasonably precise, because residents resided only at the NH during the period they converted from negative to positive. Our estimates of acquisition in the hospital are less precise, because it is possible that the resident acquired infection between the last assessment before transfer to the hospital or after returning to the $\mathrm{NH}$ following discharge from the hospital. A more precise estimate of hospital acquisition would require the ability to link $\mathrm{NH}$ assessment and hospital admission and discharge records for specific residents, which was not possible in this study. Nevertheless, with this caveat, these estimates provide a useful comparison between $\mathrm{NH}$ and $\mathrm{ACH}$ acquisition of MDROs by $\mathrm{NH}$ residents.

Among the 176,806 residents who had an active MDRO infection in the NH at any time during the study period, $61 \%$ $(108,065)$ transitioned from "no infection" (coded as 0$)$ to "infection" (coded as 1 ). Of those 108,065 residents who had a change in infection status from 0 to 1 , we found that $57 \%$ had the change occur in the NHs, $41 \%$ had the change occur in the $\mathrm{ACHs}$, and $2 \%$ had the change occur in other settings. Even though the leading source of infections seems to be $\mathrm{NHs}$, ACHs are not too far behind.

To assess the onset of MDRO infections, a cohort of res- idents were specified for whom consecutive assessments were available throughout the study period. It is critical to define a period (ie, observation unit for a resident) in which MDRO infection indicator can be specified consistently across residents and over time. Defining an observation unit for outcome variables such as "ever reported to have an MDRO infection" is challenging. There are a variety of reasons for a resident to be assessed at various time points. Additionally, many residents will not be observed during the entire study period, because they may be outside of NHs for 1 or more times. There is no readily available consistent observation unit. Therefore, we created an observation unit from the timing of assessments of all kinds. MDRO infection was included in all assessments. Because each resident is supposed to have at least a quarterly assessment, we defined our unit of observation to be a quarter per resident. For most residents, the analysis quarters were determined by the dates of consecutive quarterly assessments. For others, 1 or more analysis quarters were defined by a combination of various assessments at different times, such as 14-day, 30-day, 60-day, quarterly, admission, or discharge assessments. These residents have multiple assessments contributing to the quarterly MDRO infection indicator. This method is more accurate in capturing residents with an MDRO infection in a quarter than a method that only looks at MDRO status at a single point in time.

An analysis quarter is defined to be at least 77 days and at most 107 days. This is consistent with the MDS manual, which indicates that quarterly assessments can be done up to 2 weeks sooner. One hundred and seven days is approximately 2 weeks longer than a calendar quarter. Two alternative definitions (up to zero days longer and up to 1 week longer) were tested, but the results did not change significantly.

Even though CMS data covers all resident assessments done in the 5 calendar quarters, very few residents will have assessments covering the full 5 quarters. These are the ones who have been residents in each of the 5 quarters, had at least a total of 6 assessments in the study period ( 2 dates defines a quarter), and 2 of these assessments occurred at the very beginning of the first quarter and at the very end of the fifth quarter. The majority will have at most 4 quarters of assessments. So, the longitudinal data we created include 4 quarters, which allows for 1 baseline quarter and 3 followup quarters (Table 4). Of the 4,165,596 residents having at least 1 assessment in the study period, only 1,009,170 (24.2\%) had the minimum necessary number of days between their first and last assessments (308 days). Of the 1,009,170 residents, $730,899(72.4 \%)$ had 5 assessments separated by at least 77 days and at most 107 days.

Quarterly MDRO infection prevalence stayed steady with a slight decrease from $1.38 \%$ to $1.32 \%$ in 4 quarters. By the end of the first quarter, $0.70 \%$ of residents with no reported MDRO infections at baseline were reported to have MDRO 
infections. This new infection rate increased to $0.80 \%$ and $0.93 \%$ in the second and third quarters. By the end of the third quarter, almost $2 \%$ of residents with no reported MDRO infections at baseline were reported to have at least 1 episode of MDRO infection.

\section{DISCUSSION}

This article explores the utility of MDS data for answering a number of important research and policy questions around prevalence and transmission of MDRO infections across care settings. Our findings show that there is a very high-volume patient flow between NHs and hospitals. At least $21.5 \%$ of all older adults' national hospital episodes involve an admission from or a discharge to an NH. Therefore, MDRO infections in one setting will have implications for MDRO infections in the other setting.

We have demonstrated that the MDS data capture useful demographic, clinical, and care transition data for hospital admissions and discharges. There are signification variations in MDRO infection prevalence in NHs across sex, age, and geographical groups. Findings include that, in $\mathrm{NHs}$, male residents and younger residents are significantly more likely to have an active MDRO infection than are female residents and older residents. NHs in urban areas experience higher infection rates than do their rural counterparts. We have also demonstrated that MDS data can be used to assess MDRO transmissions across care settings. With MDS data from a longer time period, it is possible to better isolate the care setting in which MDRO infection onsets. Our findings indicate that MDRO infections are most likely to originate at $\mathrm{NHs}$, followed by ACHs.

We recommend that MDS data be used as a monitoring tool and be combined with other data sets, such as HCUP, to provide a more complete picture of HAI transmissions across care settings to inform development of guidelines for prevention of HAIs.

\section{ACKNOWLEDGMENTS}

Financial support. This work was funded by an Agency for Healthcare Research and Quality award (5R18HS01998902).

Potential conflicts of interest. All authors report no conflicts of interest relevant to this article. All authors submitted the ICMJE Form for Disclosure of Potential Conflicts of Interest, and the conflicts that the editors consider relevant to this article are disclosed here.

Address correspondence to Kalpana Ramiah, DrPH, MPH, MSC, CHES, $\mathrm{CPH}$, American Institutes for Research, 1000 Thomas Jefferson Street NW, Washington, DC 20007 (kramiah@air.org).

\section{REFERENCES}

1. Scott RD II. The direct medical costs of healthcare-associated infections in U.S. hospitals and the benefits of prevention. Atlanta: Centers for Disease Control and Prevention, 2009.
http://www.cdc.gov/HAI/pdfs/hai/Scott_CostPaper.pdf. Accessed May 20, 2014.

2. Blumenstock J, Buchanan A, Cairns C, et al. Eliminating healthcare-associated infections: state policy options. Arlington, VA: Association of State and Territorial Health Officials, 2011. http://www.cdc.gov/hai/pdfs/toolkits/toolkit-hai-policy-final _01-2012.pdf.Accessed May 20, 2014.

3. Fenton T. Healthcare reform pressures hospitals to control HAIs. Lenexa, KS: Thermo Fisher Scientific, 2010. http://www.remel .com/hai/Article.aspx?ID = 1. Accessed June 28, 2013.

4. Boucher HW, Talbot GH, Bradley JS, et al. Bad bugs, no drugs: no ESKAPE! an update from the Infectious Diseases Society of America. Clin Infect Dis 2009;48(1):1-12.

5. Gaynes R, Edwards JR. Overview of nosocomial infections caused by gram-negative bacilli. Clin Infect Dis 2005;41(6):848854.

6. Denkinger CM, Grant AD, Denkinger M, Gautam S, D'Agata EM. Increased multi-drug resistance among the elderly on admission to the hospital-a 12 -year surveillance study. Arch Gerontol Geriatr 2013;56(1):227-230.

7. Bonomo RA, Rice LB. Emerging issues in antibiotic resistant infections in long-term care facilities. J Gerontol A Biol Sci Med Sci 1999;54(6):B260-B267.

8. Raz R. The clinical impact of multiresistant gram-positive microorganisms in long-term care facilities. J Am Med Dir Assoc. 2003;4(3 suppl):S100-\$104.

9. Papia G, Louie M, Tralla A, Johnson C, Collins V, Simor AE. Screening high-risk patients for methicillin-resistant Staphylococcus aureus on admission to the hospital: is it cost effective. Infect Control Hosp Epidemiol 1999;20(7):473-477.

10. Huang SS1, Rifas-Shiman SL, Warren DK, et al. Improving methicillin-resistant Staphylococcus aureus surveillance and reporting in intensive care units. J Infect Dis 2007;195(3):330-338.

11. Lucet IC, Chevret S, Durand-Zaleski I, Chastang C, Regnier B; Multicenter Study Group. Prevalence and risk factors for carriage of methicillin-resistant Staphylococcus aureus at admission to the intensive care unit: results of a multicenter study. Arch Intern Med 2003;163(2):181-188.

12. Pop-Vicas AE, D'Agata EM. The rising influx of multidrugresistant gram-negative bacilli into a tertiary care hospital. Clin Infect Dis 2005;40(12):1792-1798.

13. Pop-Vicas A, Mitchell SL, Kandel R, Schreiber R, D'Agata EM. Multidrug-resistant gram-negative bacteria in a long-term care facility: prevalence and risk factors. J Am Geriatr Soc 2008;56(7): $1276-1280$.

14. O'Fallon E, Pop-Vicas A, D'Agata E. The emerging threat of multidrug-resistant gram-negative organisms in long-term care facilities. J Gerontol A Biol Sci Med Sci 2009;64(1):138-141.

15. Loeb MB, Craven S, McGeer AJ, et al. Risk factors of resistance to antimicrobial agents among nursing home residents. $A m$ J Epidemiol 2003;157(1):40-47.

16. Smith PW, Bennett G, Bradley S, et al. SHEA/APIC guideline: infection prevention and control in the long-term care facility. Am J Infect Control 2008;36(7):504-535.

17. Drinka PJ, Crnich CJ. An approach to endemic multi-drugresistant bacteria in nursing homes. J Am Med Dir Assoc 2005; 6(2):132-136.

18. Brennen C, Wagener MM, Muder RR. Vancomycin-resistant Enterococcus faecium in a long-term care facility. I Am Geriatr Soc 1998;46(2):157-160. 
19. Strausbaugh LJ, Crossley KB, Nurse BA, Thrupp LD. Antimicrobial resistance in long-term-care facilities. Infect Control Hosp Epidemiol 1996;17(2):129-140.

20. Bradley SF. Issues in the management of resistant bacteria in long-term-care facilities. Infect Control Hosp Epidemiol 1999; 20(5):362-366.

21. Bradley SF. Methicillin-resistant Staphylococcus aureus: longterm care concerns. Am J Med 1999;106(5A):2S-10S; discussion $48 \mathrm{~S}-52 \mathrm{~S}$.

22. Wiener J, Quinn JP, Bradford PA, et al. Multiple antibioticresistant Klebsiella and Escherichia coli in nursing homes. JAMA 1999;281(6):517-523.

23. McNeil SA, Mody L, Bradley SF. Methicillin-resistant Staphylococcus aureus: management of asymptomatic colonization and outbreaks of infection in long-term care. Geriatrics 2002;57(6): $16-18,21-24,27$.

24. Pacio GA, Visintainer P, Maguire G, Wormser GP, Raffalli J, Montecalvo MA. Natural history of colonization with vancomycin-resistant enterococci, methicillin-resistant Staphylococcus aureus, and resistant gram-negative bacilli among long-termcare facility residents. Infect Control Hosp Epidemiol 2003;24(4): 246-250.

25. Rahimi AR. Prevalence and outcome of methicillin-resistant Staphylococcus aureus colonization in two nursing centers in Georgia. J Am Geriatr Soc 1998;46(12):1555-1557.

26. Trick WE, Weinstein RA, DeMarais PL, et al. Comparison of routine glove use and contact-isolation precautions to prevent transmission of multidrug-resistant bacteria in a long-term care facility. J Am Geriatr Soc 2004;52(12):2003-2009.

27. Ben-Ami R1, Schwaber MJ, Navon-Venezia S, et al. Influx of extended-spectrum beta-lactamase-producing enterobacteriaceae into the hospital. Clin Infect Dis 2006;42(7):925-934.

28. Elizaga ML, Weinstein RA, Hayden MK. Patients in long-term care facilities: a reservoir for vancomycin-resistant enterococci. Clin Infect Dis 2002;34(4):441-446.

29. Siegel JD, Rhinehart E, Jackson M, Chiarello L; Healthcare Infection Control Practices Advisory Committee. Management of multidrug-resistant organisms in health care settings, 2006. Am I Infect Control 2007;35(10 suppl 2):S165-S193.

30. Department of Health and Human Services Office of the Assistant Secretary for Planning and Evaluation; Centers for Medicare and Medicaid Services; Health Resource and Services Administration; Department of Labor's Office of the Assistant Secretary for Policy, Bureau of Labor Statistics and Employment and Training. The future supply of long-term care workers in relation to the aging baby boom generation: report to Congress. 2003. http://aspe.hhs.gov/daltcp/reports/ltcwork.pdf. Accessed May 20, 2014.

31. Centers for Medicare and Medicaid Services. Nursing home quality initiative. MDS 3.0 for nursing homes and swing bed providers. Updated September 10, 2013. http://www.cms.gov /Medicare/Quality-Initiatives-Patient-Assessment-Instruments /NursingHomeQualityInits/NHQIMDS30.html. Accessed May 20, 2014. 